\title{
Reading English Academic Texts: Evidence from ESL Undergraduates' Eye Movement Data
}

\author{
NUR AINIL SULAIMAN \\ Faculty of Education, \\ Universiti Kebangsaan Malaysia \\ nurainil@ukm.edu.my \\ KHAZRIYATI SALEHUDDIN \\ Faculty of Social Sciences \& Humanities, \\ Universiti Kebangsaan Malaysia \\ ROZAINEE KHAIRUDDIN \\ Faculty of Social Sciences \& Humanities, \\ Universiti Kebangsaan Malaysia
}

\begin{abstract}
Reading English academic texts can be a daunting task for many ESL university students. The complex features of academic texts which include academic discourse, text structure, and vocabulary may affect the reading process. An investigation of how ESL university students read English academic reading materials would provide insights on what learners do to attain comprehension of the text. This study aims to investigate the cognitive processes that take place when ESL undergraduates read English academic texts using eye movement data. Quantitative data (total fixation duration, total fixation count, fixation duration) and qualitative data (scan path) of eye movements derived from eye tracker accompanied with retrospective interview were collected from twenty ESL undergraduates from two academic programmes. The findings revealed that participants who failed to recall the texts had longer fixation duration and resulted in more in words regressions compared to participants who recalled and explained the texts accurately. Vocabulary used in academic texts was found to be one of the factors that affect the comprehension of the texts. The findings of the study suggest that specialised instructions that emphasise academic reading skills should be implemented at the early level of tertiary education.
\end{abstract}

Keywords: English academic texts; academic reading; eye movements while reading; eye tracking; cognitive processes

\section{INTRODUCTION}

Reading is a complex cognitive process of decoding symbol (word) in order to construct or derive meaning. It involves the interaction between an array of processes and knowledge. Specifically, reading comprises basic decoding skills (such as letter recognition), higher level cognitive skills (such as inferring), and interactional skills (such as aligning oneself with an author's point of view) (Hudson, 2007). Reading also implicates visual perception which is an active process that concerns what the eyes process and what the brain interprets which brings to the visual task (Weaver, 1980). When reading takes place, the cognitive process of complex interaction between the text, the reader, and the purposes of reading, which are shaped by the reader's prior knowledge and experiences, integrate with each other to make sense of the reading. Alderson (2000) posits that knowing how and what reading is in the first place is vital before probing into various elements of reading.

In the context of second language reading, many English as a Second Language learner (ESL) may regard reading English academic texts as a daunting task. The complex features of academic texts which include academic discourse, text structure, and vocabulary may affect learners' understanding of complex contents that are usually presented in a lengthy and complex language structure. This is supported by Krashen (2011) who claims that the discourse 
and grammar of academic language can be challenging to understand, even for proficient readers. An investigation of how ESL university students read English academic reading materials would provide insights on what learners do to comprehend the text.

To examine the processes involved in reading, the use of scientific approach such as sophisticated equipment like the eye tracker to study reading processes from visual and cognitive factors can provide real-time data and detailed evidence on what happens during reading. The study of eye movements using the eye tracker has proven to be one of the most successful approaches in research on reading and hence has been used to investigate various forms of reading (Radach \& Kennedy, 2013; Salehuddin, 2018; Salehuddin et al., 2019).

\section{PURPOSE OF THE PRESENT STUDY}

The present study aimed to examine the cognitive processes that take place when ESL undergraduates read English academic texts through the eye movement data. Quantitative data (i.e., total fixation duration, total fixation count, fixation duration) and qualitative data (i.e., scan paths) of eye movements accompanied by retrospective interview were elucidated to describe how academic texts are read by ESL undergraduates.

\section{LITERATURE REVIEW}

\section{EYE MOVEMENTS IN READING RESEARCH}

Eye tracking has been a common research tool in reading research. Rayner et al. (2012) believe that eye movement data is important to understand the reading process and all the other components of reading, particularly in making inferences about the cognitive processes involved in reading. Eye movement data can function as a window for researchers to look into the mind of the readers. While reading, the eyes move in a ballistic movements (called saccades), stop, and fixate on a particular point (called fixations), or move backwards to earlier parts (called regressions), which are driven by the cognitive processes that are involved in reading.

Fixation duration is the amount of time (in seconds or milliseconds) spent on each fixation point. Total fixation duration is the amount of all fixations made in Area of Interest (AIO), while fixation duration is mean fixation calculated based on total fixation duration and total fixation count. According to Duchowski (2003), fixation duration is a good indicator to identify parts of the text or certain words that hold the reader's attention. Total fixation duration (i.e. total reading times) is widely used as one of the main measures in reading research that use eye tracking as an instrument (Elgort et al., 2017; Godfroid et al., 2017 ; Pellicer-Sánchez, 2016). According to Rayner and Morris (1990), fixation duration is related to the ease or the difficulty associated with the understanding of identified region of a text. An increase in the total fixation duration or a change in the pattern of fixation (e.g., regression) is a sign of increase on the cognitive processing involved (Raney, Campbell \& Bovee, 2014). In other words, readers' eyes will make more and longer fixations when they encounter difficulty while reading. Numerous factors affect reading and these factors result in different eye movement patterns in reading. One of the prominent linguistic features that may hinder the overall understanding of a text is the words used in the text.

Eye tracking research by Mohamed (2017) on the cognitive effects of exposure frequency in L2 reading concludes that unknown words trigger reader's attention which causes an increase in the total fixation duration, less skipping and more regressions-in rates on early 
encounters of the unknown words. In addition, repeated encounters of the unfamiliar words reduce the fixation duration spent on that word. The findings were conceded with several studies demonstrating that more and longer fixations are made on novel, unfamiliar, and/or low frequency words compared to familiar and/or high frequency words (Elgort et al., 2017; Pellicer-Sánchez, 2016 ; Godfroid, Boers \& Housen, 2013).

In addition, another eye movement measures which is regression (backward in eye movement) indicates difficulty in syntactic parsing. Regression in words or between words posits that readers experience processing difficulty to make sense or to justify the meaning of the word or sentence (Hyönä, Lorch \& Rinck, 2003; Reichle, Liversedge, Pollatsek \& Rayner, 2009). Furthermore, Conklin and Pellicer-Sanchez (2016) assert that the longer regression back in the text largely indicates comprehension failure.

In Jian and Ko's (2017) study, the eye movements recording and comprehension texts were utilised to examine the reading processes of fourth grade students with different reading abilities when reading two illustrated science texts with different levels of text difficulty. The results revealed that although high and low reading ability group spent approximately similar amount of time reading the two texts, they had different ways of reading the texts. High ability students made more regressions between text and illustration, and had longer fixations durations and more fixations on the difficult text compared to less difficult text. On the contrary, low ability students spent more time and had more attention (based on total fixation duration and fixation counts) on the less difficult text, and showed smaller number of regressions between paragraphs.

In Malaysia, eye tracking methodology in reading research is fairly new and started to gain interest among researchers in the field. Yusri and Soh's (2019) study was one of the eye tracking reading studies conducted in the Malaysian context to examine Malaysian first year university students' reading behaviours and performances from reading passages taken from Malaysia University English Test (MUET) reading text. The findings revealed that students who are less proficient in English made shorter first fixation durations on some of the reading passages, had higher rereading rates, and recorded higher percentage of regression rates compared to more proficient students.

However, most of these studies only referred to quantitative data of eye movements and discarded the qualitative aspect of eye movement data in their research. Therefore, "they do not tap into the quality of the cognitive operations that gives rise to extended processing times" (Godfroid et. al 2013, p. 509). Therefore, eye tracking data should be complemented with other performance measures, such as retrospective interviews or comprehension tests to further comprehend the underlying principles of eye movement data (Hyönä, 2010). Bax's (2013) study on investigating the test takers' cognitive processing while completing a reading test was one of the eye tracking studies that utilised both qualitative and quantitative eye tracking data coupled with stimulated recall interview. In his study, individual GazePlot (scan path) and heat map data were analysed and were corroborated with stimulated recall interview data to compare successful and unsuccessful test takers' reading behaviours in detail. The findings demonstrated that there was a significant difference between successful and unsuccessful test takers' reading behaviours on word matching, lexical synonym, grammatical levels and expeditious reading.

Scan paths are forms of graphical representation of qualitative eye movement data. Scan paths show saccadic eye movements or the links between the different points that the eyes look at when reading takes place. Such visual representation can be helpful to show the average reading behaviour of participants as the approaches are very straightforward and easy to understand compared to if the data is presented numerically. Qualitative data such as retrospective interviews and eye movement recordings complement the numerical or 
quantitative data as they provide justification and explanation of illustrated readers' behaviours and attention (Bojko, 2009).

\section{READING COMPREHENSION}

Reading comprehension is a complex cognitive task/activity involving information processing; it is highly dependent on the cognitive processes which take place as the reader progresses through the text (Yeari \& van den Broek, 2011). These cognitive processes, such as remembering the text, making inferences from the text, and integrating information from the text with existing knowledge (which are collectively known as comprehension processes), are typically associated with deeper levels of comprehension and are crucial for successful understanding of the text (Kintsch, 1998 ; van den Broek et al., 2005).

The Reading Systems Framework by Perfetti and Stafura (2014) conceptualizes the importance of knowledge sources: orthographic knowledge, linguistic knowledge, and general knowledge (knowledge about the world, e.g., text genres, text forms) in the process of reading comprehension. The framework emphasises word-level processes in a comprehensive model of reading and delineates the interaction among the three knowledge sources in reading processes. Within the framework, orthographic and linguistic knowledge influence the word identification process while linguistic knowledge and general knowledge are both significant in word comprehension process. The framework regards the reading comprehension as the word-to-text integration process where readers visually process the words by identifying their phonological, orthographical, and semantic representations, and link the words using the rule of syntax to understand the meaning of the sentence (Kendeou, McMaster \& Christ, 2016). In addition, the relevant background knowledge of the readers (i.e. general knowledge) also helps to integrate meaning across the sentences.

However, differences in skills among these knowledge sources of readers are also factors affecting the successful process of reading comprehension. Apart from that, many factors such as reader characteristics, text structure (Snow, 2002; Kulesz, 2014; Zarrati, Nambiar \& Maasum, 2014), reading self-efficacy (Shehzad et al., 2019), and text difficulty have a great influence on reading comprehension (McNamara, Graesser \& Louwerse, 2012). Text structure entails elements of a text which include vocabulary, linguistic features, discourse structure, and genre. Similar terms such as text properties, text features, and text genre are used interchangeably with text structure, which refers to the ways information is organized in a text. The text structure knowledge plays a vital role in enhancing students' reading comprehension (Zarrati, Nambiar \& Maasum, 2014). Text structure knowledge can assist readers to scrutinize how ideas in a text are inter-related through explicit or implied relationship such as sequence, comparison, causation, or problem solution that are connected in a text (Meyer \& Ray 2011).

Besides, text difficulty, which is commonly associated with readability that measures how easy a written material can be read or understood (Richards, Platt \& Platt, 1992) also influences readers' meaning-making process. The level of text difficulty is determined by several measures such as word frequency, sentence length, lexical complexity, and word length. Generally, it can be assumed that an increase in text difficulty will hinder readers' comprehension of the text. 


\section{METHODOLOGY}

\section{SAMPLING}

A total of 20 first year Malaysian ESL undergraduates at a research university in Malaysia were chosen as participants for this study. All participants had received similar number of years of English language education before entering university, and attained Band 3 or Band 4 for the Malaysian University English Test (MUET) results. They were in the same field of study (i.e. social science) but from two different academic specialisations for their bachelor's degree programme namely, Bachelor of Social Science in Psychology and Bachelor of Education in Teaching English as a Second Language (TESL). To ensure the similarity in terms of familiarity and knowledge of the structures of the academic text, the participants chosen were those had not taken any preparatory courses related to English for Academic Purpose (EAP). Hence, they had not been formally taught the structure, types, and the language skills associated with academic discourse. The data of these participants were derived from a larger sample of participants which consisted of 41 participants from the TESL programme and 38 participants from the Psychology programme. All of the participants underwent the same research procedure set by this study. However, to gain more information regarding the reading processes involved when reading English academic texts, data (i.e. total fixation duration, analysis of scan paths, retrospective interview) were elicited from 20 participants, 10 from each undergraduate programme, for a detailed analysis.

\section{READING MATERIALS}

Three academic texts (labelled as Text A, Text B, and Text C) were adapted from the introduction section of three journal articles. The introduction section of a journal is deemed suitable to be used as a stimulus (reading material) for this study as the section generally provides relevant information about the topic and does not usually contain any methodological terms that may be unfamiliar to the participants. Since content familiarity eases reading comprehension (Pulido 2004), the content of journal articles was carefully selected to ensure that the participants will be able to understand the texts. The fact that the participants were from the social sciences and humanities cluster, the journal articles chosen were on research in social sciences and humanity, and are related to university students in general. The texts were on workplace writing, technology in education and skills among graduates. Each text had four paragraphs and each paragraph was displayed on a single screen.

Out of 1217 words in the texts, $86.2 \%$ of words fall under 2000 general words of English and $13.8 \%$ of words were categorised as academic words determined by Range programme developed by Nation and Heatley (1994). These were considered adequate percentages to ensure participants' comprehension (Hu \&Nation 2000). Among all of the academic words, 12 words were among the least known academic words by ESL undergraduate students based on a study conducted by Sulaiman, Salehuddin and Khairuddin (2018). To facilitate the reading comprehension of the academic texts, glosses of four academic words were inserted on the right margin of the text. The glosses were placed in a box with blue outline, in line with the academic word in the text.

To ensure the suitability of the reading texts adapted in terms of readability, an online readability test index, Flesch reading ease (http://www.readabilityformulas.com/) of the academic texts were carried out. The readability ease scores of the three texts were 43.9 (for Text A), 36.9 (for Text B), and 26.6 (for Text C). Higher score indicates that the texts are easier to read whereas lower score suggests that the texts are more complicated and thus difficult to read. The score indicates the level of difficulty of the text and suggests the level of the readers who can read the texts. The readability scores of each of the texts showed that the texts are 
rather difficult to understand; however, they are commonly suitable for readers who are between 17 and 22 years old, and with regard to the Malaysian education system, they should range from those in their upper secondary education up to those who are in their first or second year of tertiary education.

Four experts assessed the difficulty and suitability of the texts in terms of content, and language use that suit the level of undergraduate. The experts were experienced English language educators serving in public universities and at the time the research was carried out, teaching English for Academic Purpose (EAP) courses to undergraduates from various programmes of studies. Three of them hold a master's degree in English Language Studies while one holds a master's degree in Educational Studies (TESOL). They are experienced in developing, designing, and selecting reading texts for EAP courses for their respective universities. To rate the suitability of the texts, the experts were given a checklist to complete. The checklist consists of 6 items with Yes/No options. The reliability index of the items was calculated using Cohen's Kappa measurement based on the number of items that the four interraters (four experts) agreed or disagreed. The mean kappa value obtained for Text A and Text $\mathrm{C}$ were 0.75 and 0.66 respectively, which indicated substantial agreement, while mean kappa value for Text B was 0.915 , which indicated almost a perfect agreement based on inter-rater agreement formula by Bernard and Ryan (2010).

\section{INSTRUMENTS}

The current study used TOBII TX300 Eye Tracker to investigate the participants' eye movement patterns (namely their fixation duration, fixation counts, reading time, and scan path) when reading academic texts. The eye tracker has a sampling rate of $300 \mathrm{~Hz}$ and a large head movement box which enables less restricted movements and more natural position for the respondents. The three academic texts were presented on a computer screen in regular Consolas font, size 18, double spaced. Each text consisted of four displays; each display contained 10 to 12 lines of text. A total of 12 displays were presented to the participants.

In addition, to support the data obtained from the eye tracker, a retrospective interview was conducted on each participant right after they completed reading the three texts. The questions asked on the participants' comprehension of the texts that they have read, their reading behaviours (based on scan path recording) and the text in general. The validity of the interview questions was tested in the pilot study.

\section{RESEARCH PROCEDURE}

The reading session took place individually in an eye tracking laboratory. Prior to each session, each participant was individually briefed on the research procedure and what they are expected to do during the session. All participants were asked to read the texts as they would normally do for comprehension and they were also informed about the post reading comprehension questions in retrospective interview following the reading task. The session started with a calibration test to ensure that the eye tracker detects the participants' eyes and accurately calculates the direction of his/her gaze on the screen. Next, the participants read the texts while their eye movements were recorded. There was no time limit given to the participants to read so that they could read at their own pace. To navigate to the next screen, the participants had to click on right mouse button. They were told that once they have clicked the right mouse, they could not go back to the previous page (or display) as they could only move forward to the next screen. The retrospective interviews took place right after the completion of the reading task. 
To investigate how the participants read the academic texts, the study analysed quantitative data and the qualitative data obtained from metrics available in the eye tracker and these analyses were complemented by the data from retrospective interviews.

The quantitative data for this study were total fixation duration, total fixation count and fixation duration. All of these eye movement measures were calculated based on Areas of Interest (AOIs) determined by the researcher. The AOIs for this study were the entire passage and glosses on each display and they were marked separately from one another. All the quantitative data were analysed using descriptive analysis.

The qualitative data of eye movement used for this study were videos and images of scan paths of the participants' eye movements and images of heat maps of each display. The scan path videos of the participants were analysed following Schubert's (2012) process of analysing video graphic data. The analysis comprised of detailed descriptions of the participants' eye movements according to each display, by focusing on participants' reading pattern, specifically on how the participants read each page in each text in general (i.e. rereading, regression, reading speed) and how they react with glosses provided while reading the texts. According to Holmqvist et al. (2011), regression occurs in two sizes; an "in-word" regression which is small movement backwards within a single word, "between-word" regression goes further back in the sentence. For "between-word" regression, this study looked at where the regression event occurred; regression within sentence or within line because typically, in this study, a sentence comprised of more than one line.

As for the retrospective interview data, the process of transcribing was done thoroughly based on the questions posed to the participants. The interview analysis provided justification of certain eye movement behaviours of the participants while reading. This analysis was also used to determine the participants' reading comprehension. During the interview, the participants were asked to recall each text in general and to provide a summary of each text of the text that they read. The interpretation of the participants' reading comprehension was based on their answers during the interview. This is because, comprehension of the texts should not only refer to the participants' ability to recall each text, but should also refer to their ability to accurately summarise each text and explains the text in detail.

\section{RESULTS AND DISCUSSION}

To assess the participants' comprehension of the texts, during the retrospective interview, the participants were asked what they understood from the texts. The participants were considered as "able to recall the texts" if they were able to state what each text was about generally. However, this does not mean that the participants understood the texts. The participants were considered as "have comprehended the texts" if they could accurately summarise each text and explain the texts in detail. Table 1.0 depicts the comprehension of the texts based on the analysis of the interview conducted on 20 selected participants. Pseudonymous codes were used to conceal the participants' identities. The participants from the Psychology Programme were labelled as participants P1 until P10, while the participants from the TESL Programme were labelled as T1 to T10. 
TABLE 1 . Summary of participants' comprehension of the texts

\begin{tabular}{lcc}
\hline \multicolumn{1}{c}{ Comprehension } & Psychology Programme & TESL \\
\hline & Programme \\
Recalled each text accurately & P7 & T3 \\
& & T7 \\
& & T8 \\
& P1 & T1 \\
Recalled and explained each text & P3 & T4 \\
accurately & P6 & T5 \\
& P8 & T6 \\
Failed to recall all or some of the texts & P9 & \\
& P2 & T2 \\
& P5 & T9 \\
& P10 & T10 \\
\hline
\end{tabular}

Similar number of participants from both programmes failed to recall all or some of the texts, whereas more participants from the Psychology Programme successfully recalled and explained each text accurately by providing examples and opinions when they were asked to, compared to the participants from the TESL Programme. Nevertheless, a higher number of participants from TESL Programme were only able to recall each text they read by stating the gist of each text briefly in comparison to the participants from the Psychology Programme.

Based on the interview conducted, the participants who were able to only recall the texts and those who failed to recall the texts were in the opinion that the texts were rather difficult to understand because of the presence of many unfamiliar words and the length of the texts. Some of the participants' opinions include "because too much information I need to digest." (T7), "some of the words,..I'm not familiar with" (T10), "the vocabulary..I don't know..not familiar with it" (P2). P2 who failed to recall any of the texts, found that the texts were difficult to understand. When $\mathrm{P} 2$ was asked to give reasons why he/she thought that way, P2 replied "because I read all three texts all at once, and there are some.. a bit sophisticated (word)..i never use..i don't know how to use the word" showing reading texts with different topics plus the unfamiliar words used in the texts were burdensome.

In addition, T8 who was able to recall each text accurately expressed his/her opinion on the texts, stating that the texts were "Quite hard..in terms of the words used...I don't know..some..unfamiliar words". In the same vein, P4 also found that the texts were a bit difficult, also pointing out that the words used in texts is the factor that makes the text difficult to understand. On the other hand, some of the participants (P1, P3, P6, T6) who managed to recall and explain the texts considered the texts they read to be understandable. P6 said that the texts were "not that difficult, not that easy text..university level" directing his/her opinion that the texts were fair in terms of the level of difficulty for university students.

Reading academic texts requires adequate knowledge of general vocabulary and academic vocabulary for comprehension (Choo, Ai Lin, Singh \& Ganapathy, 2017). According to Meganathan et al. (2019), adequate vocabulary knowledge is important for successful language learning and language use. Academic words that make up $10 \%$ of the vocabulary used in the texts (Coxhead, 2000) consist of low frequency words; words that are not commonly used in general English. Findings from several studies (e.g., Kamariah, Mahani \& Bordin, 2016, Harji et al., 2015, Asgari \& Mustapha, 2012) revealed that many Malaysian undergraduates do not possess adequate English vocabulary knowledge and vocabulary size; this may have presumably impeded their reading and understanding of reading material at the university level. This echoes with the participants' opinions they pointed out that some of the vocabulary used in the texts were unfamiliar and this makes the academic texts difficult to understand. From these findings, it can be assumed that inadequate English vocabulary knowledge needed to understand academic texts is most likely to have caused the participants' lack of understanding of the texts. This is worrisome as the lack of use and understanding of 
English in both academic and individual communications among Malaysian tertiary ESL learners may affect their overall academic achievement (Arifur, Rahman, Yap \& Darmi, 2018).

Table 2 shows the total fixation duration (TFD), fixation duration (FD) in seconds, and total fixation count (TFC) made by each participant based on their level of comprehension of the texts. The total fixation duration also included the fixation that occurred when readers revisited or reread the area. It also reflected the time taken by readers to complete reading the text.

TABLE 2. Eye Movements of Participants

\begin{tabular}{lcccccccccc}
\hline Comprehension & Participant & \multicolumn{3}{c}{ Text A } & \multicolumn{3}{c}{ Text B } & \multicolumn{3}{c}{ Text C } \\
& & TFD (s) & TFC & FD (s) & TFD (s) & TFC & FD (s) & TFD (s) & TFC & FD(s) \\
\hline Recalled each & P4 & 107.42 & 555 & 0.19 & 73.08 & 400 & 0.18 & 37.14 & 236 & 0.16 \\
text accurately & P7 & 192.45 & 949 & 0.20 & 138.85 & 653 & 0.21 & 147.51 & 711 & 0.21 \\
& T3 & 126.82 & 694 & 0.18 & 102.55 & 587 & 0.17 & 105.96 & 587 & 0.18 \\
& T7 & 110.75 & 601 & 0.18 & 83.81 & 479 & 0.17 & 67.12 & 391 & 0.17 \\
& T8 & 167.67 & 709 & 0.24 & 140.26 & 664 & 0.21 & 135.50 & 596 & 0.23 \\
Recalled and & T1 & 83.2 & 457 & 0.18 & 102.55 & 362 & 0.28 & 50.21 & 289 & 0.17 \\
explained each & P1 & 102.91 & 521 & 0.19 & 92.45 & 424 & 0.22 & 138.19 & 609 & 0.23 \\
text accurately & P3 & 84.71 & 483 & 0.17 & 67.78 & 392 & 0.17 & 86.85 & 489 & 0.17 \\
& P6 & 167.43 & 866 & 0.19 & 94.29 & 516 & 0.17 & 121.00 & 636 & 0.19 \\
& P8 & 103.18 & 541 & 0.19 & 96.29 & 482 & 0.19 & 83.35 & 463 & 0.18 \\
& P9 & 137.21 & 675 & 0.20 & 115.21 & 578 & 0.19 & 157.25 & 797 & 0.19 \\
& T4 & 110.15 & 519 & 0.21 & 72.81 & 332 & 0.22 & 67.18 & 310 & 0.21 \\
Failed to recall & T5 & 132.06 & 584 & 0.22 & 86.81 & 384 & 0.22 & 101.06 & 455 & 0.22 \\
all or some of & T6 & 114.32 & 546 & 0.21 & 90.91 & 445 & 0.20 & 85.67 & 444 & 0.19 \\
the texts & P2 & 108.17 & 465 & 0.23 & 113.05 & 486 & 0.23 & 108.47 & 513 & 0.21 \\
& P5 & 144.90 & 808 & 0.18 & 92.77 & 529 & 0.17 & 74.79 & 440 & 0.17 \\
& P10 & 195.46 & 817 & 0.24 & 175.07 & 709 & 0.24 & 121.37 & 508 & 0.24 \\
& T2 & 119.63 & 593 & 0.20 & 122.42 & 609 & 0.20 & 120.89 & 583 & 0.21 \\
& T9 & 102.61 & 552 & 0.19 & 113.66 & 586 & 0.19 & 126.67 & 676 & 0.18 \\
& T10 & 150.94 & 730 & 0.21 & 102.38 & 519 & 0.19 & 100.62 & 505 & 0.19 \\
\hline
\end{tabular}

Readers may read slowly in order to ensure the comprehension of a text (Carver, 1992) or they may skip words or an entire sentence when they encounter ambiguity. These circumstances also influence reading times. However, reading time or speed is not a consistent indicator of text comprehension (Wallot et al., 2014). This claim was corroborated with the findings of this study; participants P7 and T8, who took the longest time to complete reading the academic texts, were only able to recall in general what she/he had read, they failed to explain in detail what she/he had understood from the texts.

Overall, Text A yielded the longest total fixation duration compared to the two other texts for all the groups respectively. Based on scale of readability, Text A has the highest reading score readability scale which indicates lower text difficulty compared to Text $\mathrm{B}$ and Text C. According to Rayner (2009), readers make more fixations and fixate longer when they experience processing difficulty, for example, when the texts are more difficult or when readers are less skilled. Hence presumably, the participants would fixate lesser and in shorter durations while reading Text A in comparison with other texts that are more difficult. However, the data from the total fixation duration revealed otherwise. Specifically, the participants fixated longer on the first page of Text A compared to the other pages. This may be due to the fact that the participants were at the initial stage of the reading session. They spent more time on this page probably because they did not know what to expect from such a task, for example, the kind of text they were, the level of English used in the texts, and etc. Hence, more cognitive processing is needed which made the participants to fixate longer or more on certain region of the text and this caused longer total fixation duration as postulated by Raney, Campbell and Bovee (2014).

The longer total fixation duration for Text A could also be due to the fact that the content of Text A which was about workplace writing, may not be a well-known topic to the 
participants compared to the topics in Text B and Text C. The participants were only in their first semester and there is probability that they had not yet been introduced to specific writing genres such as workplace writing. They might not have adequate background knowledge of Text A content and this might have caused them to fixate longer on the text to understand it. Based on the total fixation data and fixation duration, the participants who failed to recall the texts spent a longer duration on each text compared to the participants who were able to recall and explain the texts. However, the total fixation duration of each text made by these participants (who failed to recall) collectively became shorter along the three texts. A similar pattern was observed among the participants who were able to recall the texts. As for the participants who are able to recall and explain the texts, the total fixation duration and fixation duration were the longest on Text $\mathrm{A}$, had slightly become shorter on Text $\mathrm{B}$, and made longer duration on Text $\mathrm{C}$. As mentioned earlier, in terms of readability, Text $\mathrm{A}$ is considered as the easiest, followed by Text $\mathrm{B}$ and the most difficult of the three is Text $\mathrm{C}$. The findings were rather consistent with the previous study by Jian and Ko (2017), whereby the high ability readers (in this case, the participants who comprehended the text) spent more time and longer fixation duration on the more difficult text. On the contrary, the low ability readers had longer and more fixation on easier texts.

In terms of fixation duration, the participants who failed to recall had longer fixation duration on all three texts compared to the rest of the participants. Fixation duration is commonly associated with the level of difficulty or the ease of cognitive information processing (Rayner \& Morris, 1990). The more processing time needed suggests the difficulty that the reader had in understanding the text due to many possible reasons, for examples, linguistic features of the text (Rayner \& Pollatsek, 2006). The longer fixation duration also portrays the readers' attempt to infer the meaning of unknown words (Godfroid et al., 2013) while reading.

To get more objective information regarding how the participants read the English academic texts, the scan paths of eye movements of the participants who showed understanding of the texts and those who failed to comprehend the texts were further analysed. Table 3 displays the summary of the scan path video analysis from the selected participants as they read second page (display) of each text.

TABLE 3. Summary of Scan paths

\begin{tabular}{|c|c|c|c|c|c|}
\hline & $\begin{array}{c}\text { Participants who recalled } \\
\text { and explained }\end{array}$ & & $\begin{array}{c}\text { Participants who failed } \\
\text { to recall }\end{array}$ & & $\begin{array}{l}\text { Participants who } \\
\text { recalled }\end{array}$ \\
\hline T4 & $\begin{array}{l}\text { (A2)Read the first line, and then } \\
\text { read the gloss (first reading) } \\
\text { before encounter the word. After } \\
\text { reading the second sentence, read } \\
\text { the gloss again (second time) then } \\
\text { continue reading the sentence. } \\
\text { Read the second gloss at the end } \\
\text { of reading the entire passage. } \\
\text { Regressed between words in } \\
\text { almost every line, Reread the } \\
\text { whole passage again with faster } \\
\text { reading speed and skipped more } \\
\text { words before continue to the next } \\
\text { page. (132 TFC) } \\
\text { (B2) Read the first line, and then } \\
\text { read the first gloss, regressed } \\
\text { back to the passage after read the } \\
\text { gloss. Regressed between words } \\
\text { in almost every line (103 TFC) } \\
\text { (C2) Read the passage once, line } \\
\text { by line. Read the gloss (2 } 2^{\text {nd }} \text {, }\end{array}$ & P2 & $\begin{array}{l}\text { (A2)Read word by word, line by } \\
\text { line. Skipped few articles and } \\
\text { some words. Regress between } \\
\text { words in few lines. Read the gloss } \\
\text { at the end from top to bottom. } \\
\text { (137 TFC) } \\
\text { (B2) Read word by word, line by } \\
\text { line. Skipped few article. Read the } \\
\text { gloss at the end from top to } \\
\text { bottom twice. ( } 148 \text { TFC) } \\
\text { (C2) Read word by word, line by } \\
\text { line. Regress in word "amend". } \\
\text { Regress between words in few } \\
\text { lines. Read the passage once. } \\
\text { Read the gloss at the end from top } \\
\text { to bottom. (157 TFC) }\end{array}$ & P7 & $\begin{array}{l}\text { (A2)Reread the word "confer" } \\
\text { and the word after that. Read } \\
\text { word by word, line by line. After } \\
\text { finish reading the passage for the } \\
\text { first time, reread the passage } \\
\text { starting from the second sentence } \\
\text { until the end. Skip the last line. } \\
\text { Did not look at the gloss. ( } 267 \\
\text { TFC) } \\
\text { (B2) Read the entire passage once } \\
\text { by reading it word by word, line } \\
\text { by line. Regressed between words } \\
\text { on few lines. Skip few words and } \\
\text { articles. Read the gloss at the end } \\
\text { of reading starting from bottom to } \\
\text { top gloss. (165 TFC) } \\
\text { (C2) Read the first sentence and } \\
\text { read the gloss (top) afterwards. } \\
\text { Continue reading the passage. } \\
\text { Reread the second sentence. } \\
\text { Regress in words "employability" }\end{array}$ \\
\hline
\end{tabular}




\begin{tabular}{|c|c|c|c|c|}
\hline & $\begin{array}{l}\text { bottom) before start reading the } \\
\text { passage. Regressed in word } \\
\text { "employability". Skip many } \\
\text { words in the last line and the line } \\
\text { before. ( } 86 \text { TFC). }\end{array}$ & & & $\begin{array}{l}\text { "communication", "academic". } \\
\text { Did not read the second gloss. } \\
\text { (204 TFC) }\end{array}$ \\
\hline P6 & $\begin{array}{l}\text { (A2)Read word by word, line by } \\
\text { line. Reread the first sentence. } \\
\text { Reread "albeit" and the word } \\
\text { after. Regress in words in the } \\
\text { second sentence. Regress } \\
\text { between words in few lines. Skip } \\
\text { some words in the last two } \\
\text { lines.(174 TFC) } \\
\text { (B2) Read word by word, line by } \\
\text { line. Skip most articles. Regress } \\
\text { between words in second and } \\
\text { third sentence. Did not look at the } \\
\text { gloss. (112 TFC) } \\
\text { (C2) Read word by word, line by } \\
\text { line. Read the second sentence } \\
\text { twice. Regress in word } \\
\text { "employability", "skills" and } \\
\text { reread the sentence. Skipped few } \\
\text { words at the end. Did not look at } \\
\text { the gloss. (168 TFC) }\end{array}$ & $\mathrm{T} 2$ & $\begin{array}{l}\text { (A2)Read at slightly faster pace } \\
\text { Than first page. Read word by } \\
\text { word, line by line. Skipped some } \\
\text { articles. Regress in words } \\
\text { "tends", "purpose", and few } \\
\text { more. (164 TFC) } \\
\text { (B2) Read the first line, and then } \\
\text { read the first gloss. Read word } \\
\text { by word. Regressed back to the } \\
\text { passage after read the gloss. } \\
\text { Regress in words frequently. } \\
\text { (159 TFC) } \\
\text { (C2) Skipped some articles and } \\
\text { content words in the first line. } \\
\text { Read word by word, line by line. } \\
\text { Read the first gloss after the first } \\
\text { sentence. Looked at the word } \\
\text { "albeit" longer. ( } 180 \text { TFC) }\end{array}$ & $\begin{array}{l}\text { (A2)Read the entire passage } \\
\text { once } \\
\text { Read the second sentence twice. } \\
\text { Read the forth sentence twice. } \\
\text { Regress in words "message", } \\
\text { "crucial".Did not look at the } \\
\text { gloss. ( } 131 \text { TFC) } \\
\text { (B2) Read faster, skip words } \\
\text { while reading. Regress in word } \\
\text { "confer", (117 TFC) } \\
\text { (C2) Skipped few articles and } \\
\text { more words while reading. } \\
\text { Regress between words in } \\
\text { second sentence. Regress in } \\
\text { words "albeit", "employability" } \\
\text {. Did not look at the gloss (106 } \\
\text { TFC). }\end{array}$ \\
\hline
\end{tabular}

To illustrate the visual evidence used throughout the analysis, Figure 1 shows the scan path data of participant P6 (who understood the texts), Figure 2 shows the scan path of participant P2 (who failed to recall the texts) and Figure 3 shows the scan path of participant P7 (who recalled the texts) of the second page of Text A.

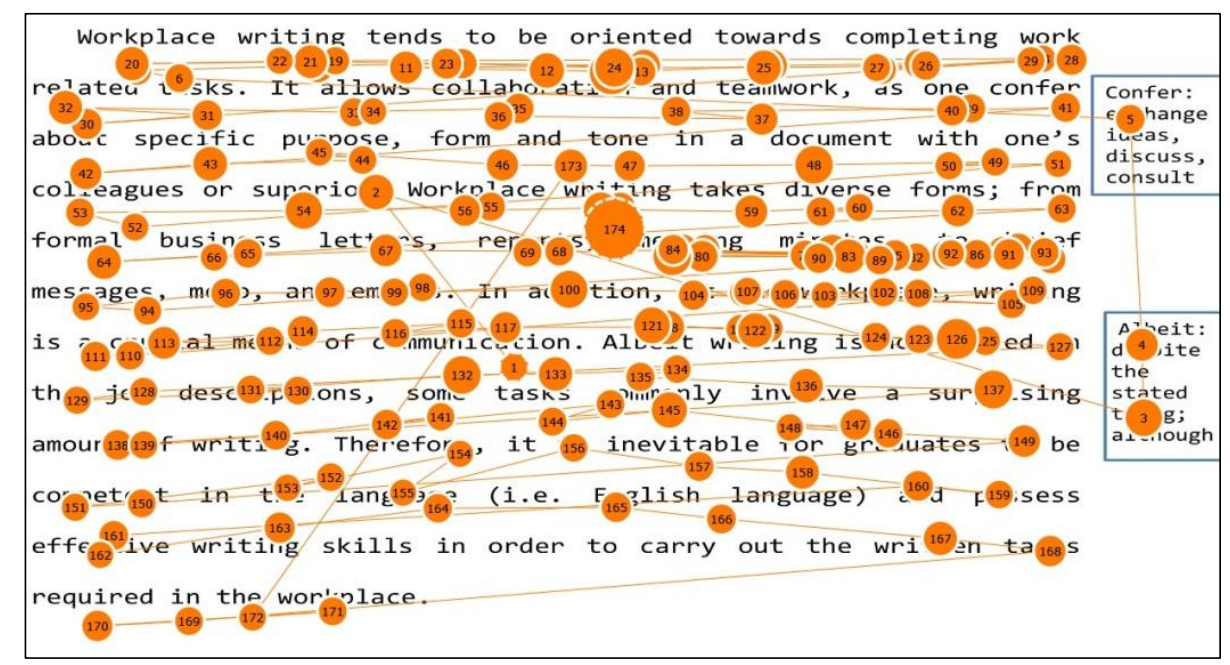

FIGURE 1. Scan path of Text A (Page 2) from P6 


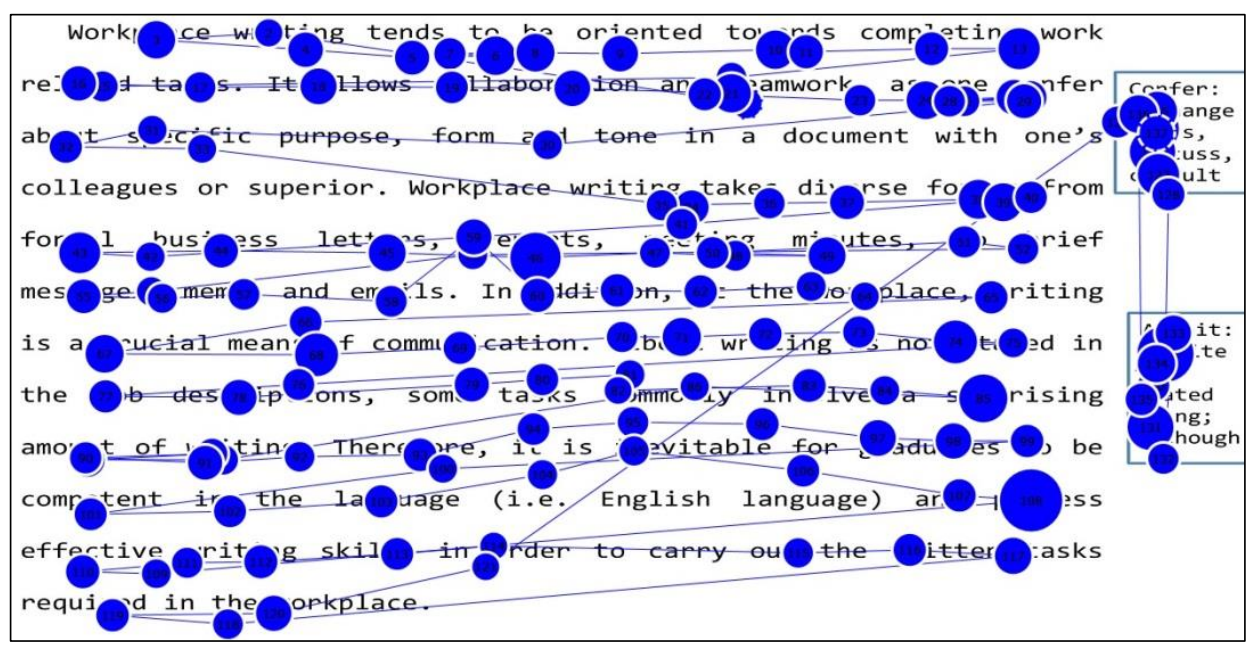

FIGURE 2. Scan path of Text A (Page 2) from P2

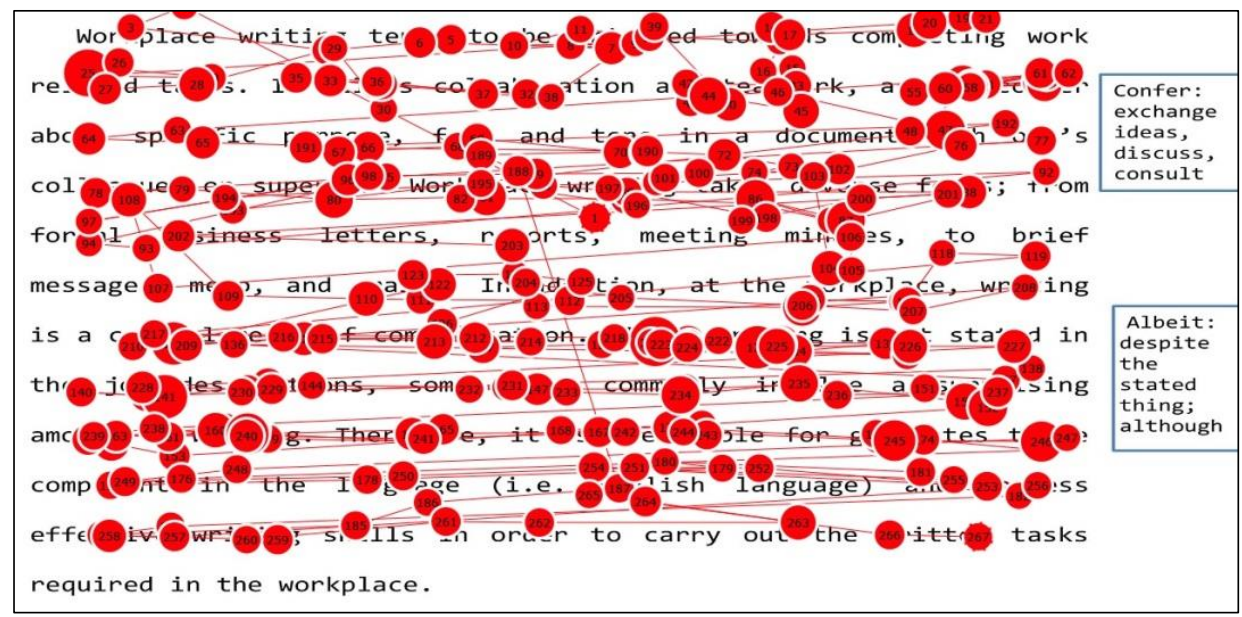

FIGURE 3. Scan path of Text A (Page 2) from P7

The scan path analysis shows that the participants read academic texts in a linear manner, that is, they read word by word and line by line. Most of the participants started to read in slightly faster pace from the second page onwards. They started to skip articles (i.e. a, the, in, on) beginning of the second page of each text. The third and fourth page of each text showed a higher number of content words skipped by the participants. The participants who understood the texts and those who successfully recalled the texts reread certain lines, sentences, or the entire passage more compared to the participants who did not understand the texts. In addition, the participants who understood the texts regressed between words (i.e., reread certain sentences or lines) more compared to regressing in words. In contrast, the participants who recalled the texts regressed between words in the same line and made more in words regressions compared to the participants who understood the texts. On the contrary, the participants who did not understand the texts made more in word regressions compared to between words regression while reading the texts. In addition, most of the participants who did not understand the texts only reread certain words or line; however they did not reread the whole sentences or passages. Regression between words occurred when the reader went back to previous line or words in the sentence or in the same line. On the other hand, regression in words indicates that the reader goes back to previous part of certain word. According to Holmqvist et al. (2011), regression in word reflects lexical activation process (understanding 
of the word), while regression between words indicates sentence integration process (how several words relate).

Rayner and Pollatsek (2006) postulate that the more regressions the reader makes, the more difficult the words or the texts are. In this case, the participants who did not understand the texts made more in word regressions, which indicates that rereading was their attempt to infer the meaning of the words. Presumably, the lack of knowledge of these words hampers their understanding of the text. On the other hand, participants who understood and were able to recall the texts made regression between words more frequently as an act to check and reconfirm what they have read. They reread certain lines or sentences to revise their understanding the texts.

These patterns of reading could depict "readers' weakness in specific knowledge sources, which then affects processes that use these knowledge sources in reading" (Perfetti \& Stafura, 2014, p 25). Based on the Reading Systems Framework, it can be interpreted that the participants who failed to recall the texts showed difficulty in word identification system whereby they faced problems in identifying the meaning of certain words which were assumed by their eye movement pattern (i.e. longer fixation duration, high in word regression). Hence, lack of word comprehension affects their overall comprehension of the texts. On the other end, the participants who succeeded in recalling and explaining the texts were in the process of integrating the meaning of the words into the representation of the text. This can be seen through their eye movements where they regressed between words in the same lines and reread certain lines or sentences in order to make sense of the texts.

\section{CONCLUSION}

This study examined how ESL undergraduates read English academic texts through their eye movement and retrospective interview. The results showed that the participants who failed to recall the texts had longer total fixation duration on each text compared to the participants who recalled and understood the texts. In addition, these participants regressed in words more frequently, while the participants who recalled and explained the texts accurately regressed between words more commonly. In other words, rereading among participants occurs in two ways; 1) reread the sentence or line, 2) reread the unknown word and the word. Based on the participants' statements, the words used in the texts were a factor that makes the texts more difficult to comprehend. All participants fixated longer on the first text even though the text was the least difficult text among the three texts. This concludes that the participants' lack of vocabulary knowledge especially in academic texts and their lack of knowledge on text structure were among the factors that affect their reading.

The findings of this study demonstrate that ESL undergraduates face difficulties when reading English academic texts especially with the vocabulary used in the texts, which then affects their understanding of the texts. Regardless of language proficiency and background knowledge, ESL undergraduates still require assistance in reading English academic texts. The findings from this study can be used as guidelines to develop reading comprehension instructions of academic texts that incorporate the learning of specialised vocabulary that will help students comprehend academic texts better. 


\section{REFERENCES}

Alderson, J. C. (2000). Assessing Reading. Cambridge Language Assessment Series, Cambridge: Cambridge University Press.

Arifur Rahman, Yap, N.T, Darmi, R. (2018). The Assosiation between Vocabulary Size and Language Dominance of Bilingual Malay- English Undergraduates. 3L: Language, Linguistics, Literature ${ }^{\circledR, ~ 24(4), ~ 85-101 . ~}$

Asgari, A., \& Mustapha, G. (2012). Vocabulary Learning Strategies of Malaysian ESL Students. Pertanika Journal of Social Sciences \& Humanities, 20(3).

Bax, S. (2003).The Cognitive Processing of Candidates During Reading Tests: Evidence from Eye Tracking. Language Testing 30(4): 441-465.

Bernard, H. R. \& Ryan, G. W. (2010). Analyzing Qualitative Data: Systematic Approaches. UK: SAGE Publication Inc.

Bojko, A. (2009). Informative or misleading?Heatmaps deconstructed. In J. Jacko (Ed.), Human-computer interaction: New trends (pp. 30-39). Berlin/Heidelberg, Germany: Springer.

Carver, R. P. (1992). Reading rate: Theory, research, and practical implications. JOurnal of Reading, 36, 84-95.

Choo, L. B., Lin, D. T. A., Singh, M. K. M., \& Ganapathy, M. (2017). The Significance of the Academic Word List among ESL Tertiary Students in a Malaysian Public University. 3L: Language, Linguistics, Literature ${ }^{\circ}, 23(4)$.

Conklin, K., \& Pellicer-Sánchez, A. (2016). Using eye-tracking in applied linguistics and second language research. Second Language Research, 32(3), 453-467.

Coxhead, A. (2000). A New Academic Word List. Tesol Quarterly, 34(2), 213-238. doi: 10.2307/3587951

Duchowski, A. (2003). Eye tracking methodology. Theory and practice. Verlag: Springer.

Elgort, I., Brysbaert, M., Steven, M., \& Assche, E. V. (2017). Contextual word learning during reading in a second language: An eye movement study. Studies in Second Language Acquisition, 1-26. doi: $10.1017 / \mathrm{S} 0272263117000109$

Godfroid, A., Ahn, J., Choi, I., Ballard, L., Cui, Y., Johnston, S., Yoon, H.-j. (2017). Incidental vocabulary learning in a natural reading context: an eye-tracking study. Bilingualism: Language and Cognition, 1-22. doi: $: 10.1017 / \mathrm{S} 1366728917000219$

Godfroid, A., Boers, F., \& Housen, A. (2013). An eye for words: Gauging the role of attention in incidental L2 vocabulary acquisition by means of eye-tracking. Studies in Second Language Acquisition, 35(3), 483517.

Harji, M. B., Balakrishnan, K., Bhar, S. K., \& Letchumanan, K. (2015). Vocabulary Levels and Size of Malaysian Undergraduates. English Language Teaching, 8(9), 119.

Holmqvist, K., Nyström, M., Andersson, R., Dewhurst, R., Jarodzka, H. \& Weijer, J. V. D. (2011). Eye Tracking. A Comprehensive Guide to Methods and Measures. United States: Oxford University Press.

$\mathrm{Hu}$, M. \& Nation, I. S. P. (2000). Unknown Vocabulary Density and Reading Comprehension. Reading in a Foreign Language and Linguistics Compass 13(403-430)

Hudson, T. (2007). Teaching second language reading: Oxford University Press Oxford.

Hyönä, J., Lorch, R., \& Rinck, M. (2003). Eye movement measures to study global text processing. The mind's eye: Cognitive and applied aspects of eye movement research, 313-334.

Hyönä, J. (2010). The Use of Eye Movements in the Study of Multimedia Learning. Learning and Instruction 20(2): 172-176.

Jian, Y.-C., \& Ko, H.-W. (2017). Influences of text difficulty and reading ability on learning illustrated science texts for children: An eye movement study. Computer \& Education, 113, 263-279. doi: http://dx.doi.org/10.1016/j.compedu.2017.06.002

Kamariah, Y., Mahani, M., \& Bordin, W. (2016). The breadth of receptive vocabulary knowledge among English major university students. Journal of Nusantara Studies, 1(1), 7-17.

Kendeou, P., McMaster, K. L., \& Christ1, T. J. (2016). Reading comprehension: Core components and processes. Behavior and Brain Sciences, 3(1), 62-69. doi: 10.1177/2372732215624707

Kintsch, W. (1998). Comprehension: A paradigm for cognition: Cambridge university press.

Krashen, S. (2011). Academic Proficiency (Language and Content) and the Role of Strategies. TESOL, 2.

Kulesz, P. A. (2014). The effects of reader characteristics, text features, and comprehension processes on reading comprehension. (Doctor of Philosophy PhD), University of Houston.

Meganathan, P., Yap, N. T., Paramasivam, S., \& Jalaluddin, I. (2019). Incidental and Intentional Learning of Vocabulary among Young ESL Learners. 3L: Language, Linguistics, Literature ${ }^{\circledR}, 25(4)$.

Mohamed, A.A. (2017). Exposure frequency in 12 reading an eye-movement perspectiveof incidental vocabulary learning. Studies in Second Language Acquisition, 1-25.

Mcnamara, D. S., Graesser, A. C., \& Louwerse, M. M. (2012). Sources of text difficulty: Across genre and grades. In J.P. Sabatini \& E.Albro (Eds.), Assessing reading in the $21^{\text {st }}$ century: Aligning and appling advances in the reading and measurement sciences. Lanham, MD: R\&L Education. 
Nation, I. S. P., \& Heatley, A. (1994). Range: A program for the analysis of vocabulary in texts [software]. Retrieved from http://www.victoria.ac.nz/lals/staff/paul-nation/nation.aspx

Pellicer-Sánchez, A. (2016). Incidental L2 vocabulary acquisition from and while reading: An eye-tracking study. Studies in Second Language Acquisition, 38(1), 97-130.

Perfetti, C., \& Stafura, J. (2014). Word knowledge in a theory of reading comprehension. Scientific Studies of Reading, 18(1), 22-37. doi: 10.1080/10888438.2013.827687

Pulido, D. 2004.The Relationship between Text Comprehension and Second Language Incidental Vocabulary Acquistion. A Matter of Topic Familiarity? Language Learning 54(233-284.

Radach, R., \& Kennedy, A. (2013). Eye movements in reading: Some theoretical context. The Quarterly Journal of Experimental Psychology, 66(3), 429-452.

Raney, G. E., Campbell, S. J., \& Bovee, J. C. (2014). Using Eye Movements to Evaluate the Cognitive Processes Involved in Text Comprehension. J Vis Exp(83). doi: 10.3791/50780

Rayner, K. (2009). Eye movements and attention in reading, scene perception, and visual search. The quarterly journal of experimental psychology, 62(8), 1457-1506.

Rayner, K., \& Morris, R. K. (1990). Do Eye Movement Reflect Higher Order Process in Reading? In G. d. Y. R. Groner, R. Parham (Ed.), From Eye to Mind: Information Acquisition in Perception, Search and Reading. North-holland: Elsevier Science Publishers

Rayner, K., \& Pollatsek, A. (2006). Eye movement control in reading. In M. J. Traxler \& M. A. Gemsbacher (Eds.), Handbook of psycholinguistics (2nd Edition ed.). Amsterdam, Netherlands: Academic Press.

Rayner, K., Pollatsek, A., Ashby, J., \& Clifton Jr, C. (2012). Psychology of reading: Psychology Press.

Reichle, E. D., Liversedge, S. P., Pollatsek, A., \& Rayner, K. (2009). Encoding multiple words simultaneously in reading is implausible. Trends in Cognitive Sciences, 13, 115-119.

Richards, J. C., Platt, J., \& Platt, H. (1992). Language teaching and applied linguistics: Logman Group UK Ltd.

Schubert, C. (2012). Video Analysis of Practice and the Practice of Video Analysis. Selecting Field and Focus in Videography. In. Knoblauch, H., Schnettler, B., Raab, J. \& Soeffner, H.-G. (eds.). Video Analysis: Methodology and Methods, Frankfurt: Peter Lang.

Shehzad, M. W., Alghorbany, A., Lashari, S. A., \& Lashari, T. A. (2019). Self-efficacy Source and Reading Comprehension: The Mediating Role of Reading Self-efficacy Beliefs. 3L: Language, Linguistics, Literature ${ }^{\circledR}, 25(3)$.

Snow, C. E. (2002). Reading for understanding: Toward an $R \& D$ program in reading comprehension. Santa Monica, CA: RAND.

Salehuddin, K. (2018). Can the eye tracker reveal how the Qur'an can be learned by heart? Al-Shajarah: Journal of the International Institute of Islamic Thought and Civilisation, 23(1), 125-147.

Salehuddin, K., Shahimin, M.M., Sulaiman, M.Z., \& Md Zolkapli, R.B. (Forthcoming, Dec 2019).Heat Maps and Scan Paths: Qualitative eye tracking evidence on how the Qur'an is memorized through reading. Journal of Nusantara Studies, (Dec).

Sulaiman, N. A., Salehuddin, K., \& Khairuddin, R. (2018). Academic word list knowledge of Malaysian ESL undergraduates. GEMA Online ${ }^{\circledR}$ Journal of Language Studies, 18(4).

Van den Broek, P. (2005). Integrating memory-based and constructionist processes in accounts of reading comprehension. Discourse Processes, 39(2-3), 299-316.

Wallot, S., O'Brien, B. A., Haussmann, A., Kloss, H., \& Lyby, M. S. (2014). The role of reading time complexity and reading speed in text comprehension. Journal of Experimental Psychology: Learning, Memory, and Cognition, 40(6), 1745-1765. doi: http://dx.doi.org/10.1037/xlm0000030

Weaver, C. (1980). Psycholinguistics and Reading. From Process to Practice. Cambridge, Massachusetts: Winthrop Publishers, Inc.

Yeari, M., \& Broek, P. v. d. (2011). A cognitive account of discourse understanding and discourse interpretation: The Landscape Model of reading. Discourse Studies, 13(5), 635-643.

Yusri, S. \& Or-Kan, S. (2019).Examining University Students' Reading Performances and Behaviours with the Use of Eye Trackers. internatinal journal of academic research in business and social sciences 9(8): 114-123.

Zarrati, Z., Nambiar, R. M. K., \& Maasum, T. N. R. T. M. (2014). The Importance of Text Structure Awareness in Promoting Strategis Reading among EFL Readers. Procedia-Social and Behavioral Sciences, 118, 537-544. 
3L: The Southeast Asian Journal of English Language Studies - Vol 26(1): 60 - 78

http://doi.org/10.17576/3L-2020-2601-05

\section{APPENDIX 1}

LAYOUT OF THE STIMULI ON THE SCREEN

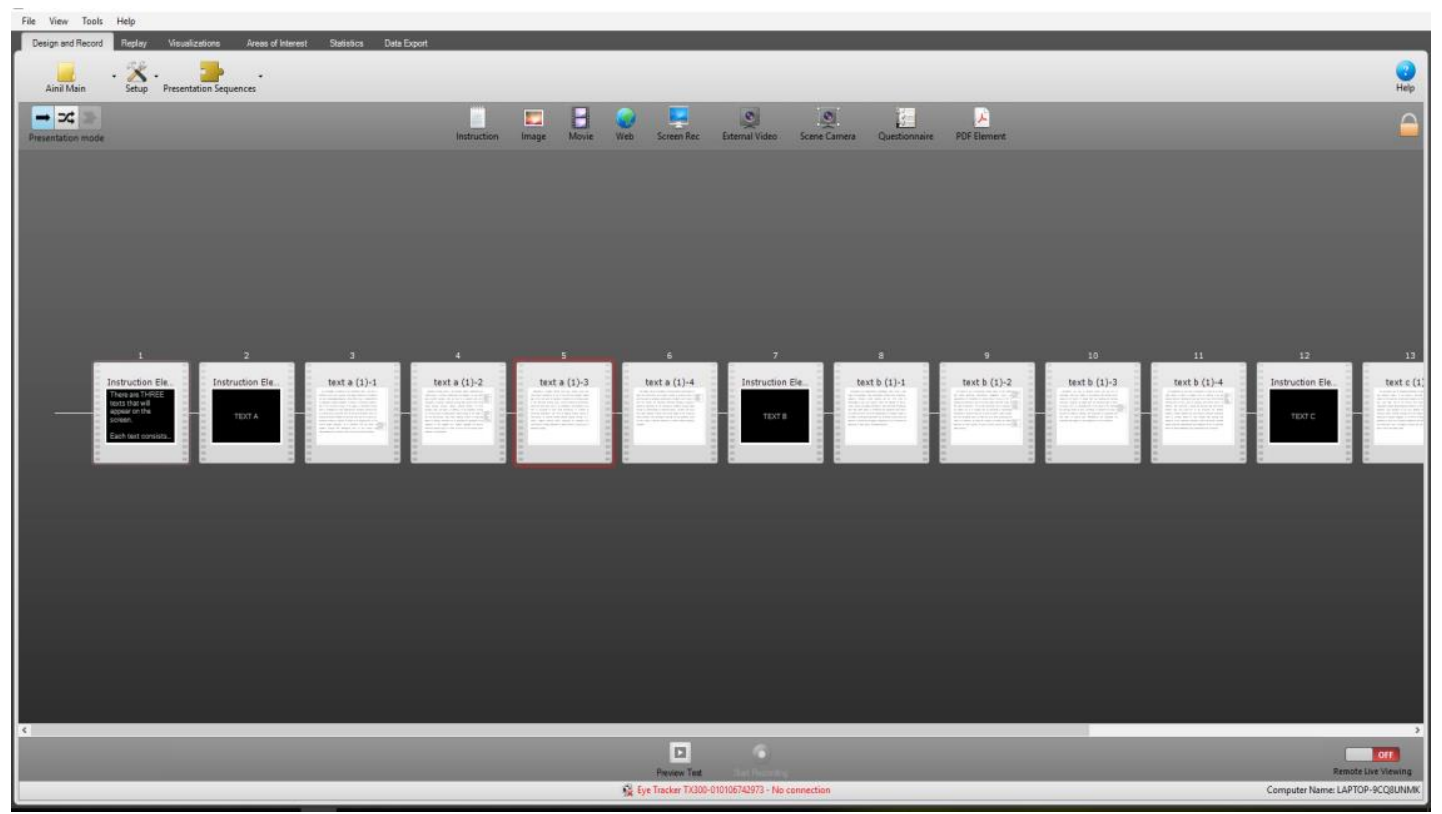




\section{L: The Southeast Asian Journal of English Language Studies - Vol 26(1): 60 - 78 \\ http://doi.org/10.17576/3L-2020-2601-05}

\section{APPENDIX 2}

\begin{tabular}{|c|c|}
\hline Text A & Text display on the screen \\
\hline 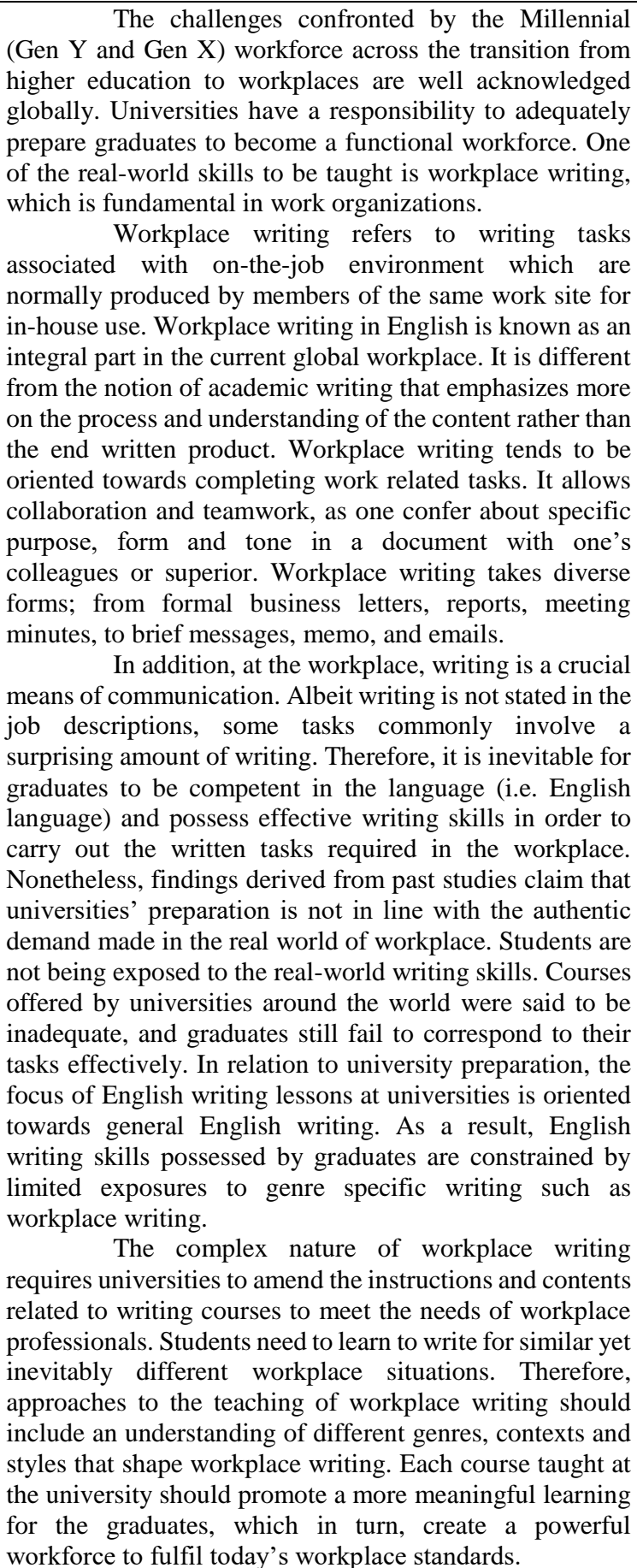 & 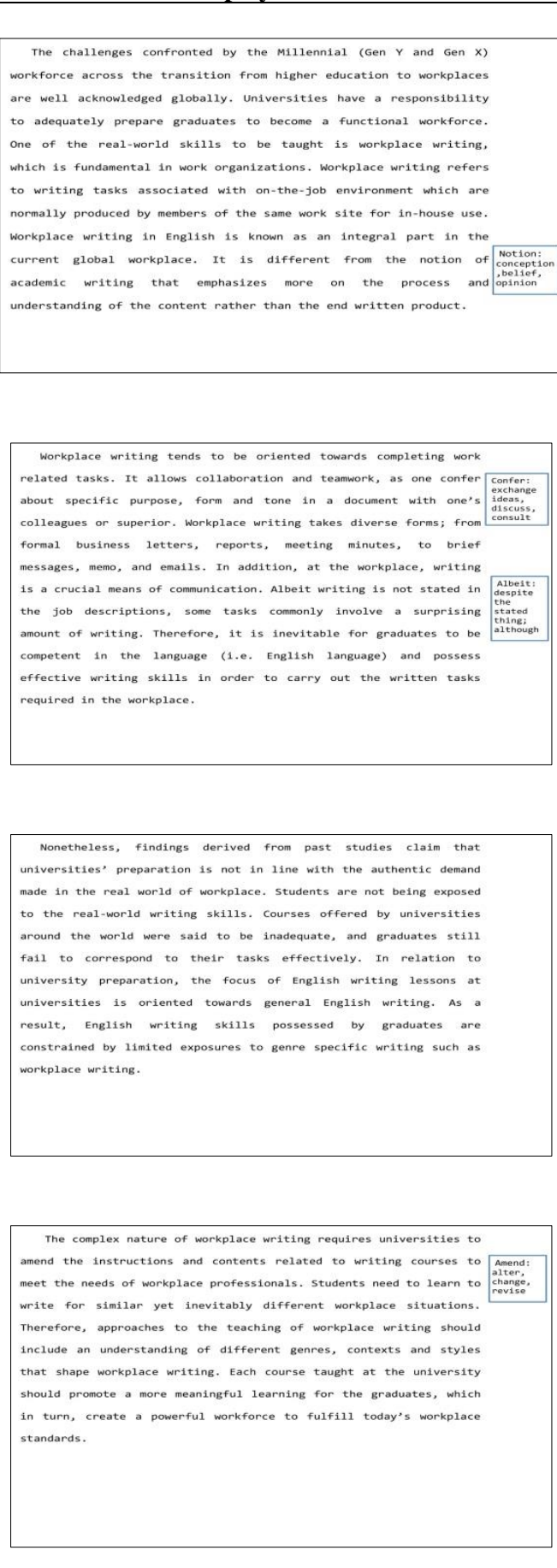 \\
\hline Text B & Text display on the screen \\
\hline $\begin{array}{l}\text { Information and communication technologies } \\
\text { (ICTs) cover a wide range of technologies. These } \\
\text { technologies include radio, television, computers, Internet, } \\
\text { social networks and etc. ICTs refer to technological tools } \\
\text { and resources which are employed to derive, create, spread, } \\
\text { and manage information. They have become information } \\
\text { tools that enable people to collaborate and communicate } \\
\text { with others all around the world. Since the implementation } \\
\text { of computer system in the 1960s, the Malaysian } \\
\text { government has introduced various plans and measures to } \\
\text { facilitate the greater integration of ICT to improve the }\end{array}$ & \\
\hline
\end{tabular}


capacities of every field, including education. The notion of ICT in educational fields refers to the systems that enable gathering, manipulation, management, access, and communication of information in diverse forms. The use of ICT in teaching and learning is one of the most widely conferred issues in the field of education. example, ICT is an integral tool in presenting or representing information in diverse forms such as texts, pictures, tables, graphs and even multimedia which can make the class more interesting and lively. In addition, by using ICT, teachers can amend the content materials for their learners to learn at their own pace as a self-study activity. Information can also be derived easily with the use of technology. There are a number of free websites that provide useful resources for teacher to design their own teaching and learning activities. Students can manage their own learning based on their own choice. This is a paradigm shift in the notion of how teaching and learning should be done. Technology in education has made it possible for students, teachers, and researchers to collaborate with each other in diverse ways.

Nonetheless, the challenges are inevitable with regards of the integration of ICT in education. The integration of ICT tools in education is still at its early stage albeit it plays an integral role in creating a new and improved model of teaching and learning. This is due to Internet access. In addition, time constraint is among the obstacles that have forced teachers away from using ICT in the classroom. The outdated hardware, limited computers and slow Internet connection inevitably cause an increase amount of time consumed when dealing with computers in the classroom. Therefore, plans and actions oriented towards effective implementation and integration of ICT in education need to be taken immediately into consideration by all parties.
ICT has many beneficial uses in education. For the limited infrastructure of ICTs, lack of training, and
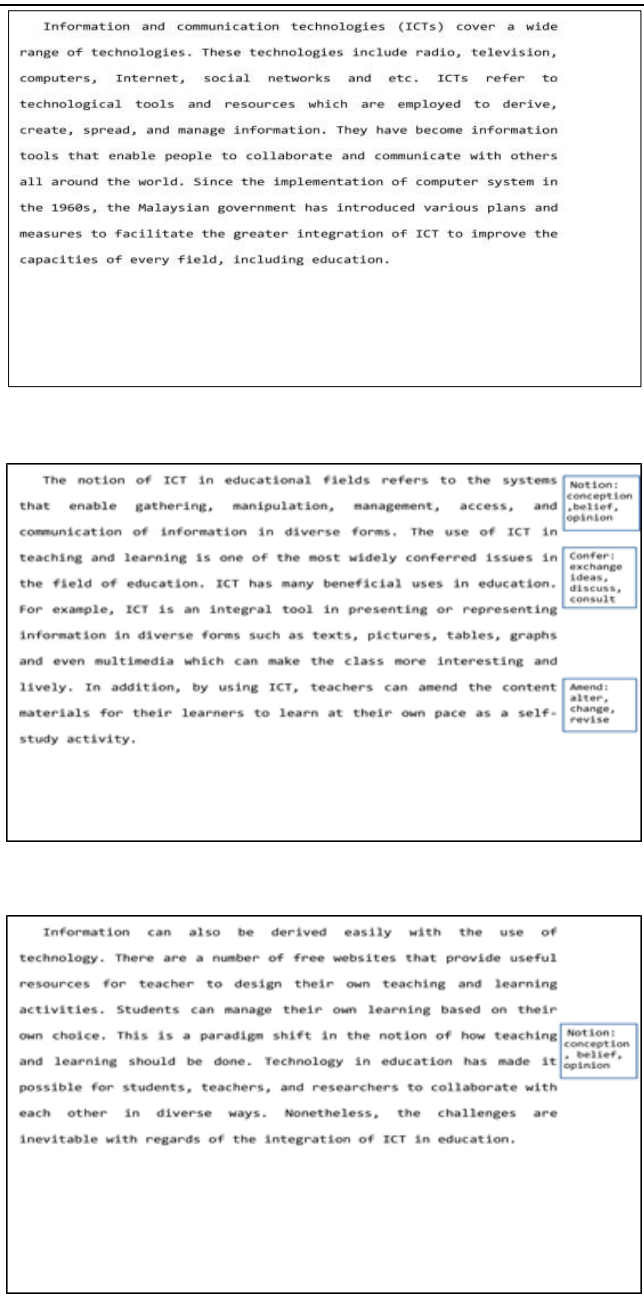

The integration of XCT tools in education is sti11 at its ear1y stage albeit it plays an integral role in creating a new and Albeit improved model of teaching and learning. This is due to the 1inited infrastructure of ICrs, lack of training, and Internet access. In thites on addition, time constraint is among the obstacies that have forced eachers away from using ICT in the classroon. The outdate hardware, 1imited computers and slow Internet connection inevitabiy cause an increase amount of time consumed when dealing with computers in the classroom. Therefore, plans and actions oriented towards effective implementation and integration of ICT in education need to be taken immediately into consideration by ail parties. Text C

The increasing rate of unemployed graduates in Malaysia has made news headlines lately. It has become a worrisome issue albeit numbers of job vacancies in Peninsular Malaysia are increasing every year since 2012. One of the factors that contribute to the unemployment problem among Malaysian graduates is the quality of the graduates. Some graduates do not have adequate skills such as technical skills, problem solving skills and communication skills, especially in English language. In an effort to adequately prepare graduates to enter the inevitably competitive job market nowadays, the university's role is integral to ensure that the graduates are able to fulfil the market needs. Orientation solely on academic achievement is not enough, as broader skills or employability skills are required to amend the quality of job seekers and graduates to be highly marketable. 


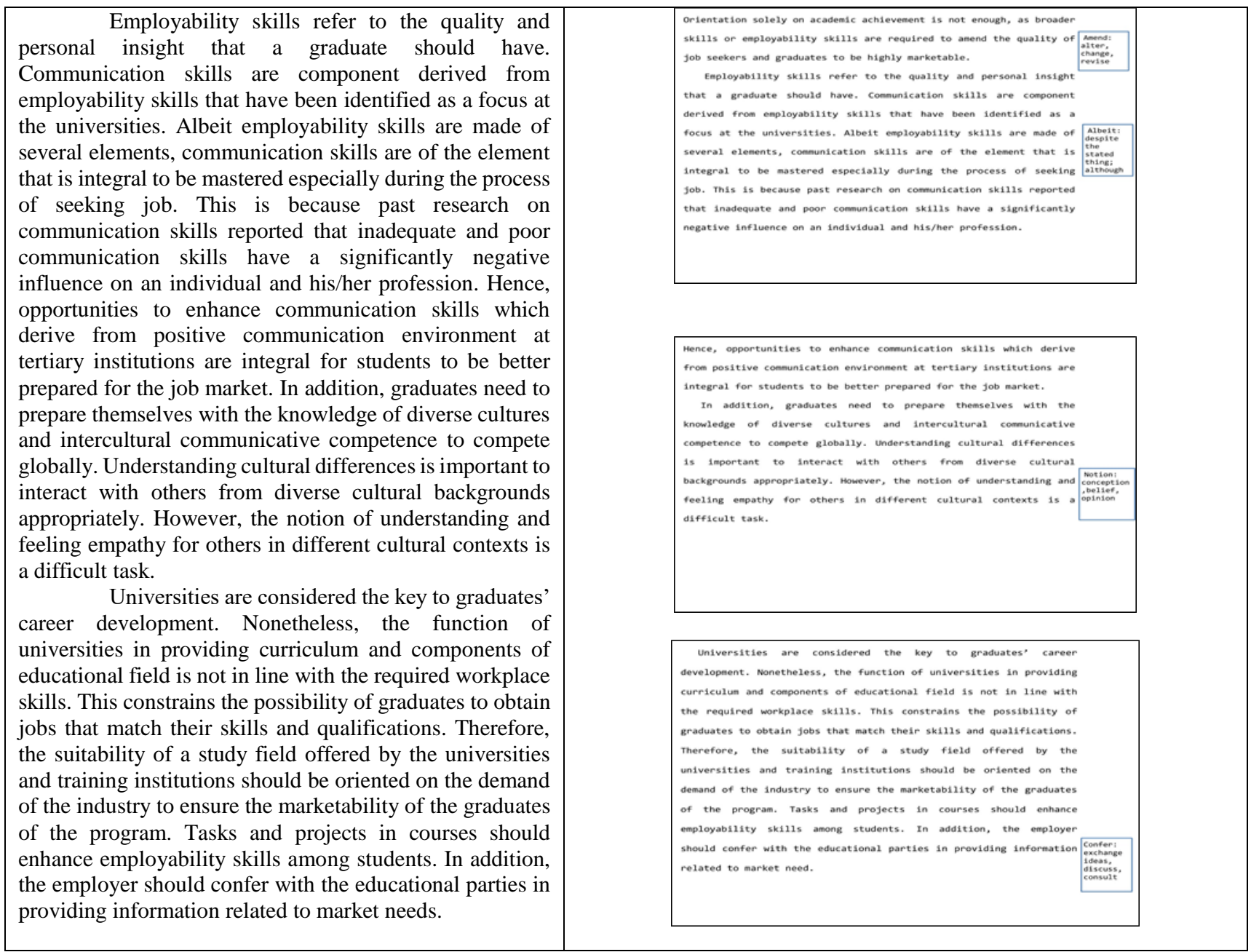

